DOCTRINA

\title{
Hacia la creación de un derecho penal internacional del medio ambiente
}

\author{
Towards the creation of an international criminal law for the environment
}

\author{
Elena de Luis García (iD \\ Universitat de València, España
}

\begin{abstract}
RESUMEN El medio ambiente sigue sufriendo graves ataques: incendios, contaminación, deforestación y caza ilegal, son solo algunos de los problemas que acechan al medio natural y que, tras décadas de evolución del derecho del medio ambiente, siguen sin afrontarse de forma adecuada y eficaz. Es indudable la repercusión que las condiciones ambientales tienen sobre el conjunto de la humanidad y, por ello, en aras de la propia supervivencia de la especie humana y del conjunto de seres vivos con quienes compartimos el planeta, quizá ha llegado la hora de que el derecho penal internacional intervenga en su defensa. Así pues, el objeto del presente trabajo es realizar una aproximación a la situación actual del medio ambiente en el derecho penal internacional y humanitario, así como a las distintas posibilidades a través de las cuales podría configurarse un crimen internacional contra el medio ambiente, bajo el Estatuto de Roma de la Corte Penal Internacional.
\end{abstract}

PALABRAS CLAVE Medio ambiente, derechos humanos, impunidad, derecho penal internacional, Corte Penal Internacional.

ABSTRACT The environment is still suffering serious attacks: fires, pollution, deforestation and illegal hunting, are only some of the problems that threaten the natural environment and that, after decades of evolution of environmental law, are still without solution. It is undeniable the effect that environmental conditions have over humanity, for that reason, in order to ensure the survival of human beings and the living beings that share the planet with us, maybe it is time for international criminal law to intervene. Therefore, the aim of this paper is to approach the current situation of environment in international criminal law and humanitarian law, as well as the different possibilities to create an international crime against the environment under the Rome Statute of the International Criminal Court. 
KEWYWORDS Environment, human rights, impunity, international criminal law, International Criminal Court.

\section{Introducción}

En las últimas décadas, el medio ambiente ha pasado de ser una preocupación secundaria a ocupar los titulares en medios de comunicación de todo el mundo. Grandes catástrofes asolan nuestro planeta y, día tras día, lo observamos desde mayor o menor distancia, en muchas ocasiones sin poder intervenir de ningún modo. Así, la contaminación, los incendios, la deforestación o el tráfico de especies protegidas son solamente algunos de los riesgos que amenazan al medio ambiente con respecto a los cuales carecemos de herramientas adecuadas para hacer frente. Uno de los grandes problemas con el que nos topamos es con la impunidad que suele presidir un elevado número de casos, lo que conlleva que determinados hechos que afectan al conjunto del planeta y de la humanidad queden sin investigar y enjuiciar y, en consecuencia, se perpetúen en el tiempo. Las causas de ello obedecen, en algunas ocasiones, a la existencia de intereses económicos o políticos, pero, en muchas otras, simplemente a problemas de prueba, de determinación de la competencia judicial o, en definitiva, a la insuficiencia de medios adecuados para la investigación de los delitos. Es por ello que suele hablarse de una impunidad fáctica y no normativa, porque no se produce por ausencia de tipos penales, sino por la falta de persecución (Ambos, 2004: 86).

A mayor abundamiento, esta situación se ha visto agravada por la pandemia de la enfermedad covid-19, pues lo que a corto plazo se veía como una posibilidad de reducir las emisiones y, con ello, el calentamiento global, está resultando en una disminución de recursos económicos que ponen al medio ambiente en una situación de desprotección. La escasez de personal de vigilancia y control, la disminución del turismo y la necesidad de recurrir a otros medios para subsistir son solo algunas de las circunstancias que están provocando, entre otras, el aumento de la caza furtiva o la destrucción de espacios naturales.

Ante esta situación, desde distintos sectores se viene planteando hace años la posibilidad de configurar un crimen internacional contra el medio ambiente del que sería competente la Corte Penal Internacional. La doctrina mayoritaria lo ha denominado «ecocidio». Cabe recordar que el establecimiento de la Corte Penal Internacional respondió a una necesidad de frenar la impunidad en los crímenes más reprochables, como reza el Preámbulo del Estatuto de Roma del 17 de julio de 1998 de la Corte Penal Internacional. Ahora bien, existen multitud de elementos que deben ser valorados, por un lado, para decidir si puede o no intervenir el derecho penal internacional y, por otro, para configurar adecuadamente un crimen en este ámbito y garantizar que solamente las agresiones más graves sean objeto de tutela en el ordenamiento penal internacional. 
Así, el objetivo de este trabajo es, en primer lugar, plasmar cuál es la situación actual del medio ambiente en el derecho penal internacional y, en segundo lugar, realizar una aproximación a la forma en que podría configurarse un crimen internacional contra el medio ambiente. Es decir, qué elementos debería incluir el tipo delictivo y qué conductas son las que podrían castigarse a través de este ordenamiento. Para ello, comenzaremos haciendo algunas reflexiones en torno a la relación entre el medio ambiente y los derechos humanos, y cómo dicha relación no fue solamente una de las circunstancias que favoreció la aparición del derecho penal ambiental, sino que también es el fundamento para la intervención del derecho penal en materia de protección del medio ambiente.

A partir de ahí, podremos realizar algunas consideraciones en torno a la creación de un posible crimen internacional contra el medio ambiente, cuya tipificación podría contribuir a la prevención y castigo de los ataques más graves contra el medio ambiente y, en última instancia, a la mejora en la protección ambiental a nivel global, tanto para las generaciones presentes como las futuras.

\section{Medio ambiente, derechos humanos y derecho penal}

Es importante mencionar que 1972 marcó un antes y un después en la protección del medio ambiente, ya que por vez primera se reconocía a nivel internacional su relación con los derechos humanos y la necesidad de preservarlo no solo para las generaciones presentes, sino también para las futuras, lo cual se plasmó en la Declaración de Estocolmo adoptada en la Conferencia de Naciones Unidas sobre el Medio Humano, celebrada en dicha ciudad en junio de $1972 .{ }^{1}$ Así, su Principio 1 establece que:

El hombre tiene derecho fundamental a la libertad, la igualdad y el disfrute de condiciones de vida adecuadas en un medio de calidad tal que le permita llevar una vida digna y gozar de bienestar, y tiene la solemne obligación de proteger y mejorar el medio para las generaciones presentes y futuras.

Por su parte, el Principio 2 añade la necesidad de preservar el medio ambiente «en beneficio de las generaciones presentes y futuras», lo que supone el nacimiento de una obligación intergeneracional de evitar un daño futuro (Lawrence, 2015: 33-34).²

Este texto fue criticado por parte de la doctrina al considerar que no realizaba una protección expresa ni tampoco imponía obligaciones a los Estados, quedando, por lo tanto, en una declaración de intenciones sin efecto vinculante (Atapattu, 2002: 74 y 81). Sin embargo, su importancia es mayúscula, no solamente por ser la primera

1. «Declaración de Estocolmo adoptada en la Conferencia de Naciones Unidas sobre el Medio Humano», Organización de las Naciones Unidas, 5 a 16 de junio de 1972, disponible en bit.ly/3mMDmtO.

2. En el mismo sentido, puede verse Shelton (2015) y Hiskes (2005). 
vez que se reconoce a nivel internacional la incidencia de las condiciones del medio ambiente en los derechos humanos, sino porque trajo como consecuencia la iniciación de una ola de reformas a nivel global que conllevó la incorporación de los derechos ambientales en la mayoría de las constituciones del mundo (Boyd, 2012: 112-113). Dos décadas después, la Declaración de Río adoptada en la Conferencia de Naciones Unidas sobre medio ambiente y desarrollo, celebrada en junio de 1992, ${ }^{3}$ venía a completar la labor iniciada por su predecesora, desarrollando una serie de derechos de acción ambiental, con la finalidad de reforzar la protección del medio ambiente y el desarrollo sostenible. A diferencia de la anterior, este texto sí que incorporó medidas específicas y políticas para hacer efectivos los derechos protegidos (Ewing-Chow y Soh, 2009: 205).

Como decimos, uno de los grandes logros de la Declaración de Estocolmo fue la incorporación en numerosas constituciones del derecho a un medio ambiente sano o adecuado. Además, cabe señalar que tanto la Convención Americana de Derechos Humanos como la Carta Africana de Derechos Humanos y de los Pueblos protegen explícitamente el derecho a un medio ambiente adecuado. ${ }^{4}$ Por el contrario, el Convenio Europeo de Derechos Humanos no reconoce expresamente ningún derecho ambiental, de forma que ha sido el Tribunal Europeo de Derechos Humanos quien ha interpretado el contenido de los derechos a la vida, el respeto de la vida privada y familiar o la propiedad privada, entre otros, incorporando el derecho al medio ambiente sano en su ámbito de protección (Pedersen, 2011: 470-471).5

Dejando a un lado su previsión normativa, lo cierto es que el derecho al medio ambiente ha sido objeto de un amplio debate alrededor de su naturaleza y contenido. Así, ha habido distintas corrientes doctrinales en torno a su naturaleza de derecho de tercera generación (Franco del Pozo, 20oo: 11-12; Vernet i Llobet y Jaria i Manzano, 2007: 516), pero también en torno a si debía considerarse un derecho autónomo o un derecho instrumental (Matellanes, 2008: 39-40; Borrás Pentinat, 2014: 651), en el sentido de depender de otro derecho para su vigencia. El único aspecto en el cual parece no haber habido discusión es en su relación con la dignidad humana (Ferrete Sarria, 2006: 153), considerándose que la vida será digna en tanto exista un grado de calidad ambiental que permita el desarrollo de la propia vida humana con la satisfacción de

3. «Conferencia de Naciones Unidas sobre medio ambiente y desarrollo», Organización de las Naciones Unidas, 3 a 14 de junio de 1992, disponible en bit.ly/3mShtcm.

4. Por lo que respecta a la Convención Americana sobre Derechos Humanos (CADH), se recoge el derecho a un medio ambiente adecuado en el artículo 11 del Protocolo Adicional a la CADH en materia de derechos económicos, sociales y culturales, «Protocolo de San Salvador», adoptado el 17 de noviembre de 1988. En el caso del sistema africana, en el artículo 11 de la Comisión Africana de Derechos Humanos y de los Pueblos (CADHP).

5. Para un extracto de la jurisprudencia más relevante, puede verse Factsheet - Environment and the European Convention on Human Rights, disponible en bit.ly/2HPyIMp. 
las necesidades básicas (Pallemaerts, 2002: 19). En definitiva, sin un medio ambiente adecuado no puede haber una vida digna.

Compartimos la posición de Loperena Rota, quien entiende que el medio ambiente sano o adecuado no es fruto de la evolución social - lo que caracterizaría a los de tercera generación-, sino que se erige como presupuesto para la vida misma, así como condición fundamental para el desarrollo de la humanidad, por lo que el Estado no los crea, sino que debe reconocerlo y protegerlo, igual que ocurre con los derechos de primera generación (Loperena Rota, 1999: 4; Loperena Rota, 2008: 82). La premisa para sustentar esta afirmación es que sin medio ambiente no puede haber vida y, por lo tanto, no cabe la existencia humana ni disfrute de los demás derechos. Es decir, el medio ambiente incide directamente en los derechos fundamentales más básicos como la vida o la integridad física. Es por todo ello por lo que entendemos que el medio ambiente es y debe ser considerado un derecho, y no un derecho instrumental, sino un derecho autónomo, entendido como aquel que permite a las personas desarrollarse en un medio ambiente adecuado que garantice unas condiciones de vida digna.

A partir de lo anterior, podríamos afirmar que el nacimiento del derecho penal ambiental obedeció fundamentalmente a un hecho clave: el reconocimiento o, en otras palabras, la toma de conciencia de la importancia de las condiciones ambientales sobre la vida y la salud humana en el sentido expuesto supra. Es decir, si la vida humana tiene la entidad suficiente para ser protegida a través del derecho penal y el medio ambiente incide directamente en su disfrute, este debe ser merecedor también de tutela a través del derecho penal. Ello sin perjuicio de que podamos reconocer que los propios elementos del medio natural son también dignos de protección penal por sí mismos, pero, en la medida en que estamos hablando de derechos, adoptaremos una visión y justificación basada fundamentalmente en la incidencia del medio ambiente sobre las personas.

Volviendo al nacimiento del derecho penal ambiental, esto se produce en el contexto de la denominada «sociedad del riesgo», término acuñado por Beck (1992) para referirse a un escenario caracterizado por la aparición de nuevos riesgos que se derivan de la industrialización y el avance tecnológico. La sociedad del riesgo influye directamente sobre la política criminal y se crean nuevos tipos delictivos para prevenir o minimizar esos riegos, lo que conlleva que el derecho penal se convierta en un instrumento de minimización de esos riesgos basado en la protección de derechos sociales (Sieber, 2016: 15). Esta situación provoca una expansión del derecho penal que se caracteriza por la aparición de nuevos delitos referidos a la tutela de intereses supraindividuales y la punición del peligro (Barona Vilar, 2017: 46). Se busca proteger bienes que antes eran abundantes y a los que se otorga un nuevo valor, como ocurre precisamente con el medio ambiente (Silva Sánchez, 2001: 25). 
Cabe señalar que ha habido - y sigue habiendo- una fuerte crítica desde algunos sectores a la tutela del medio ambiente a través del derecho penal. En este sentido, se ha criticado por considerarse un derecho penal simbólico (Muñoz Lorente, 2001: 126-127), pero también por su ineficacia debida a la carencia de medios adecuados, la permisividad y arbitrariedad de los poderes públicos y la deficiente técnica legislativa (Jorge Barreiro, 2005: 19), todo lo que ha llevado a que se afirmase que el derecho administrativo sancionador podría ser suficiente (Silva Sánchez, 1997). Sobre esto, Faure y Svatikova (2012: 284-285) opinan que las sanciones administrativas tampoco han demostrado su completa eficacia, por lo que lo ideal es un sistema que combine ambos en función de la gravedad del ataque al medio ambiente. En cuanto al carácter simbólico, en la línea de Corcoy Bidasolo (2010: 51-52) entendemos que será positivo, en la medida en que contribuya al reconocimiento social de la importancia del bien jurídico protegido y su única función no sea la simbólica.

Anteriormente, decíamos que el medio ambiente es necesario para el desarrollo de la vida humana y que incide de forma directa en la calidad de vida, en la salud $y$, en definitiva, en la dignidad de las personas. Es por ello por lo que se puede afirmar que si el derecho penal tiene como una de sus funciones proteger los bienes jurídicos socialmente más relevantes de las agresiones más graves y si por esos bienes entendemos aquellos fundamentales para la autorrealización y desarrollo de las personas, no cabría duda de que el medio ambiente es uno de ellos (Mendo Estrella, 2007: 184-185). En efecto, la protección del medio ambiente es esencial para las personas, la flora y la fauna, por lo que cualquier daño actual o potencial al patrimonio natural es merecedor de intervención del derecho penal, ya que pone en riesgo la vida misma de las personas (Vervaele, 2016: 127). Siguiendo la misma línea, se ha justificado la protección penal del medio ambiente en la existencia de una obligación de las generaciones presentes de conservar el medio ambiente para las futuras (Schünemann, 1997: 190-194).

No podemos sino mostrarnos de acuerdo con las anteriores afirmaciones, ya que, conforme hemos expuesto, la protección del medio ambiente se vincula de forma directa a las condiciones de vida humanas, de forma que negarle relevancia se presenta difícil. Por lo tanto, si la vida y la integridad física son merecedoras de protección penal, ¿por qué no habría de serlo el medio ambiente cuando influye de forma directa en su disfrute? Por todo esto, no podemos sino concluir que, efectivamente, el medio ambiente goza de entidad suficiente para ser protegido por el derecho penal y así es precisamente como se encuentra tutelado en la mayor parte de los ordenamientos jurídicos nacionales. 


\section{Medio ambiente y derecho penal internacional}

Sentado lo anterior, el siguiente paso será examinar hasta qué punto la magnitud de los daños al medio ambiente puede conllevar la intervención del derecho penal internacional. Como punto de partida, cabe destacar que el medio ambiente fue objeto de discusión en los debates previos a la adopción del Estatuto de Roma de la Corte Penal Internacional, cuando la Comisión de Derecho Internacional de Naciones Unidas asumió la tarea de redactar un código de crímenes contra la humanidad. Así, en el borrador inicial fueron incluidos los daños intencionales y graves contra el medio ambiente como un crimen internacional, si bien se descartó su inclusión definitiva, ya que varios miembros de la Comisión plantearon que, de producirse daños ambientales de tal entidad, podrían ser castigados de acuerdo con los crímenes de guerra o el terrorismo intencional, así como en virtud de la Convención sobre la prohibición de utilizar técnicas de modificación ambiental con fines militares u otros fines hostiles de 1976 (Convención ENMOD). Es decir, se consideró que la existencia de otras figuras podría bastar para proteger el daño ambiental a través del derecho penal internacional. ${ }^{6}$ Sin embargo, como veremos, el limitado ámbito de aplicación y excesivas condiciones exigidas para la aplicación de las normas existentes hacen que no gocen de utilidad real para la protección del medio ambiente.

En concreto, son dos instrumentos de derecho internacional humanitario los que recogen una mención al medio ambiente dentro de los crímenes de guerra: la Convención ENMOD, arriba citada, y el Protocolo I adicional a los Convenios de Ginebra de 1949 relativo a la protección de las víctimas de los conflictos armados internacionales, aprobado el 8 de junio de 1977.

Por lo que respecta a la Convención ENMOD, tiene por objeto la prohibición a los Estados parte de «utilizar técnicas de modificación ambiental con fines militares $\mathrm{u}$ otros fines hostiles que tengan efectos vastos, duraderos o graves, como medios para producir destrucciones, daños o perjuicios a otro Estado Parte», de conformidad con su artículo 1. Si acudimos al artículo 2, por técnica de modificación ambiental se refiere a cualquier que tenga por objeto «alterar - mediante la manipulación deliberada de los procesos naturales- la dinámica, la composición o estructura de la Tierra, incluida su biótica, su litósfera, su hidrósfera y su atmósfera, o del espacio ultraterrestre». Lo más relevante de las definiciones aportadas por la Convención es la necesidad de que las técnicas de modificación ambiental produzcan efectos que sean vastos, duraderos o graves, no siendo necesario que se den las tres condiciones, sino que bastará con una de ellas (Leebaw, 2014: 778). Si acudimos a su anexo, el texto define qué se entiende por cada una de esas circunstancias. Así pues, «vasto» hace

6. Puede verse el Informe de la Comisión de Derecho Internacional sobre la labor realizada en su 47. ${ }^{\circ}$ período de sesiones (2 de mayo-21 de julio de 1995), Doc. A/5o/10. Disponible en bit.ly/2HT4mZp. 
referencia a que afecte a una superficie de cientos de kilómetros cuadrados; «duradero» implica que los efectos permanezcan durante varios meses o lo que dura una estación; $\mathrm{y}$ "grave» se refiere a que la perturbación o daño sea significante para la vida humana, los recursos naturales y económicos u otros bienes. ${ }^{7}$ Una de las críticas que se hace a esta regulación es que se restringe a los conflictos armados internacionales y, específicamente, a los existentes entre dos Estados parte (Dinstein, 2001: 530; Halpern, 2015), por lo que no tendrá una gran aplicación práctica, máxime si tenemos en cuenta que la gran mayoría de conflictos armados que se producen en el mundo son internos.

Por su parte, el régimen establecido por los Convenios de Ginebra no presenta un mejor escenario, ya que sus condiciones son aún más restrictivas. El Protocolo I, en sus artículos 35.3 y 55, prohíbe el empleo de métodos o medios de hacer la guerra destinados a causar o de los que quepa prever que causen «daños extensos, duraderos y graves al medio ambiente natural», añadiéndose la prohibición de efectuar ataques al medio ambiente como represalia. En este caso, nos topamos con varios obstáculos. El primero de ellos sería la falta de definición de los términos «extensos, duraderos y graves», aunque podríamos salvarlo acudiendo por analogía a la definición contenida en el anexo de la Convención ENMOD antes referido. El segundo sería, en la línea de la citada Convención, que su ámbito de aplicación se restringe exclusivamente a los conflictos armados internacionales. El tercer y último obstáculo sería que, a diferencia de la Convención ENMOD, las condiciones de extensos, duraderos y graves de los efectos son acumulativas, lo que implica que deben darse necesariamente las tres para que sea de aplicación el precepto (Black, 2008: 119-120).

En definitiva, el régimen establecido por las normas de derecho internacional humanitario se plantea de difícil aplicación, fundamentalmente por el hecho de que quede restringido a situaciones de conflicto armado y que, además, deben ser de ámbito internacional.

Junto a los anteriores textos, el Estatuto de Roma de la Corte Penal Internacional regula los crímenes de guerra en su artículo 8 y, en concreto, recoge la producción de daños al medio ambiente en el apartado 2.b.iv) de dicho precepto, aunque, lejos de suponer un avance con respecto a los textos ya citados, anteriores en el tiempo, lo cierto es que el régimen previsto se muestra aún más restrictivo. En concreto, el artículo referido castiga la siguiente conducta: «Lanzar un ataque intencionalmente, a sabiendas de que causará $[. .$.$] daños extensos, duraderos y graves al medio ambiente$

7. Texto original: «It is the understanding of the Committee that, for the purposes of this Convention, the terms, «widespread», «long-lasting» and «severe» shall be interpreted as follows: (a) «long-lasting»: lasting for a period of months, or approximately a season; (b) «severe»: involving serious or significant disruption or harm to human life, natural and economic resources or other assets; (c) «widespread»: encompassing an area on the scale of several hundred square kilometres». 
natural que serían manifiestamente excesivos en relación con la ventaja militar concreta y directa de conjunto que se prevea».

Esta disposición no solamente adolece de los mismos obstáculos y límites que las formulaciones de la Convención ENMOD y el Protocolo I de los Convenios de Ginebra, sino que, además, añade una dificultad añadida y es que el autor de los hechos debe hacerlo a sabiendas de que el ataque causará los daños al medio ambiente «extensos, duraderos y graves». Ello, como decimos, es una dificultad añadida para su aplicación, ya que exige un conocimiento por parte del perpetrador que va más allá de la intencionalidad del ataque para abarcar también la entidad de las consecuencias de este. Pero es que, además, los daños deben ser «manifiestamente excesivos en relación con la ventaja militar concreta y directa de conjunto que se prevea», lo que, de la redacción del precepto, parece que también debe ser conocido por el autor de los hechos. Por lo tanto, se deberá probar que el autor era conocedor de que el ataque causaría daños ambientales de la magnitud descrita en el precepto y que, conociendo dichas consecuencias, lanza intencionadamente el ataque (Lawrence y Heller, 2007: 74-84). En cuanto al carácter de «manifiestamente excesivos» de los daños, en la definición del crimen realizada por la Corte Penal Internacional se indica que se tendrá en cuenta la legalidad de la actividad militar dentro de un conflicto armado. ${ }^{8}$ Por último, deberemos acudir nuevamente a la Convención ENMOD para interpretar qué se entiende por «extensos, duraderos y graves», condiciones que, además, son acumulativas y de gran entidad, por lo que es una barrera añadida para la persecución de los crímenes (Smith, 2013: 55). Además, se ha criticado también que, bajo esta configuración, los ataques aislados al medio ambiente quedarían sin cobertura por no estar integrados en un ataque militar a gran escala (Drumbl, 1998, 125).

Para mejorar este precepto o, dicho de otro modo, facilitar su aplicación práctica, debería, por un lado, ampliarse su ámbito al de los conflictos armados internos $-\mathrm{y}$ no únicamente internacionales- $y$, por otro, reconfigurar algunos de sus elementos y definiciones. Sobre esto, cabría sustituir el requisito de haber cometido el acto de forma intencional $\mathrm{y}$ «a sabiendas» por exigir un conocimiento razonable de las posibles consecuencias de los actos, y, del mismo modo, que la calificación de los daños como «manifiestamente excesivos» se sustituyera por «excesivos» (Black, 2008: 126).

Al margen de lo anterior, cabe señalar que en septiembre de 2016 la Oficina del Fiscal de la Corte Penal Internacional publicó las directrices sobre la selección y priorización de casos y se hizo constar que, a la hora de evaluar la gravedad de un crimen, se tendría en cuenta si el mismo se ha perpetrado, entre otras circunstancias, con la

8. Para más información, véase International Criminal Court, Elements of crime. The Hague: 2013, p. 13. Disponible en https://bit.ly/34P3sq4. 
intención o resultado de destruir el medio ambiente. ${ }^{9}$ Asimismo, se añadió en dicho documento que se prestaría especial atención a los crímenes cometidos con la intención o resultado de destruir el medio ambiente, explotar ilegalmente recursos naturales o arrebatar tierras a sus pobladores. Ello no implica, obviamente, que fuesen a salvarse los obstáculos puestos de manifiesto, ya que estos forman parte de la definición de los crímenes de guerra y no pueden modificarse, pero sí que implicó, cuanto menos, que el medio ambiente comenzaba a tener cierta relevancia en el ámbito del derecho penal internacional.

En todo caso, como decimos, sigue habiendo un escollo insalvable -incluso aunque se modificase el precepto en el sentido expuesto anteriormente-, que sería su restricción a los conflictos armados, en tanto que, en definitiva, estamos hablando de la regulación de los crímenes de guerra. Es precisamente esta barrera la que quiere superarse y para lo cual se han formulado las distintas propuestas que seguidamente presentaremos.

\section{Propuestas para una mejora de la protección ambiental en el ordenamiento penal internacional}

Conforme hemos visto, el régimen bajo el que actualmente se penalizan los daños al medio ambiente en el derecho penal internacional es el de los crímenes de guerra, lo que implica que únicamente serán punibles cuando los daños se produzcan en el seno de un conflicto armado y concurran el resto de circunstancias o elementos que prevén las normas anteriormente citadas. Sin embargo, existen numerosos daños al medio ambiente de magnitud y efectos globales que tienen lugar fuera de un conflicto y que, por tanto, quedarían fuera del ámbito del derecho penal internacional en la actualidad. Asimismo, muchos de ellos no se cometen de forma intencionada o conociendo los posibles efectos, sino que se producen como consecuencia de una conducta imprudente que acarrea consecuencias desastrosas. Por ello, debemos preguntarnos no solamente si podríamos castigar como crimen internacional los daños ambientales fuera de conflicto armados, sino también los daños causados por imprudencia grave.

\section{Perspectivas actuales a la luz del régimen vigente en el Estatuto de Roma}

Vamos a partir de que el preámbulo del Estatuto de Roma define su ámbito como el de «los crímenes más graves de trascendencia para la comunidad internacional en su conjunto», aquellos que «constituyen una amenaza para la paz, la seguridad y el

9. Para más información, véase Office of the Prosecutor, Policy paper on case selection and prioritisation, International Criminal Court, 2016. Disponible en https://bit.ly/34Lxdb3. 
bienestar de la humanidad». Bajo esta concepción, los atentados más graves contra el medio ambiente deberían ser considerados crímenes internacionales en la medida en que cumplen los presupuestos, esto es: tener efectos transnacionales y afectar a intereses fundamentales o derechos humanos (Mégret, 2011: 240) conforme hemos puesto de manifiesto.

Ahora bien, a pesar de que no puede negarse la relevancia del medio ambiente en el conjunto de la humanidad, lo cierto es que los crímenes internacionales definidos en el Estatuto de Roma de la Corte Penal Internacional comparten otras características, además de la trascendencia para la comunidad internacional, y son la intencionalidad y el conocimiento. En este sentido, el artículo 30 dispone que «una persona será penalmente responsable y podrá ser penada por un crimen de la competencia de la Corte únicamente si los elementos materiales del crimen se realizan con intención y conocimiento de los elementos materiales del crimen». Por lo que respecta a la intención, lo define como la actuación de una persona que se propone incurrir en una conducta o causar una consecuencia. Por su parte, el conocimiento se refiere a la conciencia de que concurre una determinada circunstancia o se va a producir una consecuencia. Ello implica que el Estatuto de Roma castiga tanto el dolo directo como el dolo de consecuencias necesarias - el autor sabe la consecuencia segura de sus actos- y el dolo eventual - sabe que la consecuencia es posible- (Laurenzo Copello, 2000: 100).

Sin embargo, en la historia hay registro de grandes tragedias ambientales y humanas ocurridas por imprudencia grave de las personas responsables o encargadas en cada caso, como son, a título de ejemplo, el accidente nuclear de Chernóbil ocurrido el 26 de abril de 1986 o el desastre de Bhopal en 1984. Ambos casos comparten la característica de tener trascendencia para el conjunto de la humanidad, pero carecen del elemento de intencionalidad y conocimiento exigido en el Estatuto de Roma. Si se definiese un crimen internacional contra el medio ambiente que penase las acciones por imprudencia grave, desastres como los antedichos podrían llegar a ser enjuiciados en el ámbito del derecho penal internacional, siempre respetando su carácter complementario con respecto a los ordenamientos nacionales de acuerdo con el artículo 17 del Estatuto de Roma.

En los últimos años, se ha discutido de qué formas podrían contemplarse los delitos medioambientales más graves en el ámbito del derecho penal internacional, como autónomos e independientes de los crímenes de guerra.

Algunos autores se han planteado si cabría incardinar los atentados más graves contra el medio ambiente dentro de los delitos de genocidio, pero el dolo específico que requiere este crimen hace prácticamente imposible esta solución. Cabe recordar que, de acuerdo con el artículo 6, el genocidio se define como la destrucción de un grupo por una de las cuatro causas previstas: nacionalidad, etnia, raza o religión, lo que implica que bastaría con que el autor de los ataques al medio ambiente alegase 
que su intención no era destruir un grupo, sino que únicamente lo hizo por intereses económicos o de otra naturaleza para que ya no pudiese calificarse su conducta de conformidad con el Estatuto de Roma (Smith, 2013: 48-49).

Otra opción, quizá más factible, sería calificar los crímenes ambientales como crímenes contra la humanidad, pues en este caso basta con que se produzca «un ataque generalizado o sistemático contra una población civil y con conocimiento de dicho ataque», según el artículo 7. Ello supone que para calificar un hecho como crimen contra la humanidad podría ser suficiente con que el autor de este fuese consciente de que su conducta constituye un ataque sistemático contra la población civil, con independencia de que la motivación fuese una u otra (Smith, 2013: 51). Sin embargo, entendemos que la inclusión de los daños ambientales más graves en la figura de los crímenes contra la humanidad resultaría en una protección insuficiente de acuerdo con el objetivo que se busca con la intervención del derecho penal internacional en materia medioambiental. Esto es así en tanto que esta solución excluiría aquellos casos en que se producen graves daños al medio ambiente natural, sin afectación directa sobre las personas, los cuales, como después se expondrá, entendemos que sí que deberían incluirse en la hipotética definición de un crimen internacional contra el medio ambiente.

Los anteriores obstáculos han llevado a que las voces mayoritarias aboguen por la creación de un crimen independiente, como el quinto crimen de competencia de la Corte Penal Internacional al que se ha denominado «ecocidio».

\section{Configuración de un crimen internacional contra el medio ambiente}

En torno a la posible configuración de un crimen internacional contra el medio ambiente ha habido numerosas propuestas, algunas de las cuales repasaremos a continuación.

Una de las acepciones que mayor acogida ha tenido es la que planteó Higgings, que definía el crimen de ecocidio como el daño, destrucción o pérdida de ecosistemas en un determinado territorio, bien sea por acción humana u otras causas de una magnitud que el disfrute pacífico de los habitantes de dicha zona se vea gravemente afectado (Higgins, Short y South, 2013: 257; Higgins, 2010). De esta definición cabe destacar que castigaría el daño, aun cuando el origen del mismo fuese natural, siempre que pudiese nacer una responsabilidad por infracción del deber de cuidado por parte de las autoridades (Higgins, Short y South, 2013: 257).

Por su parte, Gray (1996: 216-218) identificaba el ecocidio como una vulneración de derechos humanos intencionada o imprudente, en la cual concurren los siguientes elementos: daño ambiental severo, extenso, duradero y de consecuencias internacionales, al que añade la existencia de intereses económicos minoritarios que no reportan beneficio a la comunidad e ignoran tanto el daño que causan como la existencia de otras alternativas más eficientes. Por lo que respecta a las condiciones señaladas, el 
autor entiende que deberá valorarse la extensión geográfica, el número de afectados, la dificultad o imposibilidad de revertir el daño y el nivel de relevancia para la comunidad internacional o implicación de personas de distintas nacionalidades entre las víctimas y los autores (Gray, 1996: 216-218).

Otros autores han empleado el término "geocidio» para referirse a los ataques más graves contra el medio ambiente con la particularidad de que, en este caso, se centrarían más en los daños naturales que los humanos. En este sentido, Berat (1993: 342-343) define el geocidio como la destrucción intencional de cualquier elemento del ecosistema a través de las siguientes acciones: matanza de especies, provocación de daños físicos a las mismas, imposición de condiciones de vida que acarrearían su destrucción o imposición de medidas que impidan el nacimiento de estas. La autora traslada los elementos propios del genocidio al crimen de geocidio, justificando la tipificación en que la disminución de la biodiversidad afecta al derecho de las personas a un medio ambiente sano, el cual debe protegerse a través del derecho penal internacional. Cabe señalar que la principal crítica a esta configuración fue la efectuada por Gray, quien consideraba que resultaría más fácil de aplicar el crimen de ecocidio como él lo definía al no requerir el elemento de intencionalidad ni la destrucción de especies (Gray, 1996: 216).

Resulta también interesante traer a colación las propuestas de Nieto Martín (2012: 144-152), quien define tres figuras distintas en función de si el daño es causado sobre las personas, los elementos del medio natural o el patrimonio. Así, la primera sería el ecocidio, que se referiría a la destrucción de un grupo humano a través de daños ambientales y exigiría dolo en la actuación. La segunda sería el geocidio, que consistiría en la producción de daños ambientales de gran magnitud y dimensión internacional para cuya comisión bastaría con una imprudencia grave. Por último, el autor define el patrimonicidio como la destrucción del patrimonio de una comunidad a través de la destrucción de los recursos naturales, de comisión únicamente dolosa (Nieto Martín, 2012: 144-152).

De todas las definiciones anteriores, cabe sacar varias conclusiones. La primera y más evidente, que no existe consenso doctrinal acerca de qué elementos debería incluir un crimen internacional contra el medio ambiente. Pero, además, que hay dos cuestiones sobre las que existen diferentes posiciones y que son fundamentales a la hora de definir el posible crimen: por un lado, si se debería exigir la producción de un daño directo a las personas o si bastaría con el daño natural (en todo caso, toda destrucción del medio natural conlleva implícito un daño para el ser humano); y, por otro lado, si se podría castigar una conducta imprudente o debería exigirse, en todo caso, una intencionalidad o, al menos, un dolo eventual. Junto a estos elementos, consideramos que no puede olvidarse la problemática que causa la determinación del tipo de resultado exigido y la naturaleza de norma penal en blanco que suele caracterizar a los delitos contra el medio ambiente. 


\section{Intencionalidad o imprudencia}

Como se ha señalado, el artículo 30 del Estatuto de Roma recoge la intencionalidad como un elemento esencial en los crímenes competencia de la Corte. En concreto, castiga tanto el dolo directo como el dolo de consecuencias necesarias y el dolo eventual (Laurenzo Copello, 2000: 100). Sin embargo, muchas catástrofes ambientales son producidas como consecuencia de una imprudencia grave, como el accidente de Chernóbil en Ucrania o el del buque Prestige en las costas españolas. Por dicho motivo, consideramos que deberían tipificarse también los daños severos al medio ambiente provocados por imprudencia grave, con la finalidad de dar cobertura a una parte importante de las más graves catástrofes medioambientales. De este modo, se castigaría el dolo directo, el dolo eventual y la imprudencia grave, en consonancia con la tipificación habitual de los delitos contra el medio ambiente en la mayor parte de ordenamientos jurídicos nacionales.

\section{Riesgo o lesión}

Otro elemento de suma importancia es determinar si bastará la puesta en riesgo del bien jurídico protegido para integrar la conducta típica o si será necesario que se produzca un resultado lesivo, es decir, que efectivamente se cause un daño al medio ambiente. Partimos de que, generalmente, los delitos contra el medio ambiente son delitos de peligro. Más allá de la discusión en torno al tipo de peligro, ${ }^{10}$ lo cierto es que no se exige la producción de un resultado lesivo para que la conducta sea constitutiva de delito medioambiental, lo que se justifica porque en materia ambiental no se puede esperar a que se produzca el daño, sino que es necesario anticiparse y evitarlo.

Sin embargo, en el ámbito del derecho penal internacional consideramos que debería castigarse únicamente la conducta cuando se produzca un resultado lesivo, de forma que integremos el concepto, reflejado en el propio Estatuto de Roma, de «agresiones más graves a los derechos humanos».

\section{Naturaleza del daño exigible}

Otro aspecto a determinar es si en la definición del ecocidio deben incluirse únicamente aquellas conductas que causen un daño directo sobre las personas o si bastaría con la ocurrencia de graves daños al medio ambiente natural.

En este sentido, podría alegarse que la producción de daños estrictamente naturales no debería ser sancionada en el ordenamiento penal internacional, ya que este tiene como uno de sus fines velar por los derechos humanos, de forma que si no se afectase de forma directa ningún derecho de las personas, no podríamos tipificar la

10. Para la discusión en el ámbito de la doctrina española, puede verse de Luis García (2019). 
conducta en este ámbito. No obstante, no puede negarse que el medio ambiente es fundamental para el desarrollo de la vida humana, tanto que constituye el presupuesto para nuestra propia existencia, lo que conlleva que cualquier incidencia sobre el medio ambiente tenga consecuencias directas o indirectas sobre las personas, tanto las generaciones presentes como las futuras (Mehta y Merz, 2015: 6-7; Sharp, 1999: 243). Por ello, entendemos que no cabe exigir una lesión directa, sino que nos mostramos de acuerdo con Berat en el sentido de que cualquier ataque a la naturaleza es un atentado al derecho a un medio adecuado (Berat, 1993: 342-343), pudiendo servir la definición de un crimen internacional contra el medio ambiente el cauce para concretar qué límites de destrucción ambiental se consideran tolerables y a partir de los cuales el derecho ha sido lesionado (Lytton, 2000: 81-82). De este modo, estaríamos protegiendo la naturaleza, aunque el fundamento de la protección sea su incidencia sobre los seres humanos.

\section{Remisión a normas extrapenales}

La mayoría de los delitos contra el medio ambiente se definen como normas penales en blanco, esto es, que requieren de otra norma para completarlas, o, dicho en otras palabras, que configuran un supuesto de hecho por remisión a otras normas del ordenamiento jurídico que no son de naturaleza penal (Muñoz Conde y García Arán, 2015: 40-42). En el caso que nos ocupa, el de los delitos medioambientales, esa remisión suele efectuarse a normas administrativas reguladoras de cuestiones ambientales.

A la hora de configurar un crimen internacional contra el medio ambiente tendríamos que valorar si es recomendable configurarlo como una norma penal en blanco y, en su caso, a qué normas se efectúa la remisión, es decir, qué normas integran la conducta típica y determinan la ilicitud de la conducta a efectos penales. Desde luego, la solución idónea sería que existiese un adecuado desarrollo del derecho internacional en materia de medio ambiente, de forma que se pudiese efectuar la remisión a dicho cuerpo normativo. Otra posibilidad sería remitir a normativa nacional, pero no parece aconsejable, pues la legislación difiere enormemente de unos Estados y unas regiones a otras, a lo que debemos sumar la complejidad que implicaría la determinación del derecho aplicable en aquellos casos en que la conducta afecte al territorio de más de un Estado. Por otro lado, la falta de remisión a normas extrapenales podría efectivamente conllevar serios problemas en la definición de las conductas.

En síntesis, no parece que exista ninguna solución que sea completamente acertada, sin embargo, atendiendo a las circunstancias actuales de desarrollo del derecho internacional ambiental, consideramos que una solución sería definir el ecocidio por la propia actuación y resultado causado, sin necesidad de que se produzca una remisión a normas extrapenales. 
En relación con lo anterior, aún faltaría determinar cómo definir la conducta de forma que su ámbito de aplicación quedase restringido a aquellos casos en los cuales el daño es de trascendencia para la comunidad internacional en conjunto o, dicho de otro modo, de tal entidad que toda la humanidad se vea afectada por su comisión. Siguiendo a Smith (2013: 62), podríamos emplear la misma terminología que la Convención ENMOD y, por lo tanto, exigir que los daños causados al medio ambiente fuesen extensos, duraderos y graves. Todo esto implicaría, según hemos expuesto supra, que podría tipificarse como crimen internacional la producción de daños al medio ambiente de forma dolosa o por imprudencia grave que afecte a varios cientos de kilómetros cuadrados, cuyos efectos perduren durante varios meses o lo que dura una estación y que afecten de forma significativa a la vida humana o los elementos naturales, lo que también incluye el daño grave a los ecosistemas, la calidad del agua, la calidad del aire, la calidad del suelo, la fauna o la flora.

\section{Conclusión}

De lo expuesto en este trabajo hemos extraído tres conclusiones principales. En primer lugar, que el medio ambiente guarda una estrecha relación con el disfrute y vigencia de los derechos humanos, lo que implica que cualquier alteración en el medio es susceptible de causar una lesión es un derecho de las personas. Por esto, al medio ambiente se le atribuye la cualidad de derecho, entendido como el derecho a desarrollarse en un medio ambiente sano o adecuado que permita las condiciones adecuadas para una vida digna. En segundo lugar, que, debido a dicha repercusión sobre los derechos de las personas, el medio ambiente es merecedor de tutela penal. Si el derecho penal interviene para proteger algunos de los bienes jurídicos más básicos y fundamentales de las personas como la vida o la integridad física y estamos defendiendo que el medio ambiente influye directamente sobre los mismos, entonces el derecho penal también puede intervenir para proteger el medio ambiente. En tercer lugar, que esa influencia del medio ambiente sobre las personas es de tal magnitud que sus ataques afectan al conjunto de la humanidad, amenazan a la supervivencia de la especie $y$, en definitiva, son de trascendencia para la comunidad internacional, motivo por el que los crímenes más graves y reprochables contra el medio ambiente podrían ser susceptibles de tipificación a través del derecho penal internacional, como crímenes internacionales.

En relación con lo anterior, hemos expuesto algunas de las posibilidades que existirían para configurar un delito contra el medio ambiente en el Estatuto de Roma de la Corte Penal Internacional, llegando a la conclusión de que los elementos principales deberían ser la tipificación del daño causado tanto a las personas como a los elementos del medio ambiental natural, la penalización de la comisión del delito por imprudencia grave, la definición de la conducta sin remisión a normas extrapenales 
y la exigencia de un resultado lesivo. De ese modo, reiterando lo expuesto, podría proponerse como crimen internacional contra el medio ambiente la producción de daños ambientales, sea mediante una actuación dolosa o por imprudencia grave que afecte a varios cientos de kilómetros cuadrados, cuyas consecuencias perduren durante varios meses o lo que dura una estación y que afecten de forma significativa a la vida humana o los elementos naturales, lo que también incluiría el daño grave a los ecosistemas, la calidad el agua, la calidad del aire, la calidad del suelo, la fauna $o$ la flora.

Además, aun cuando por las propias limitaciones del presente no haya podido abordarse la cuestión, será necesario plantearse qué régimen de responsabilidad se establecería y qué régimen de reparación del daño natural causado. Por lo que respecta al primer elemento, nos referimos a si debe mantenerse la responsabilidad personal que recoge el Estatuto de Roma o si podría ser el momento de incorporar a dicho texto la responsabilidad penal de las personas jurídicas, aun cuando en su momento ya se descartó por falta de consenso. En cuanto al segundo elemento, nos estamos refiriendo al desarrollo de un sistema a partir del cual la Corte Penal Internacional pueda ordenar la forma en que se deba llevar a cabo la reparación del daño causado al medio natural, así como quién deba ejecutar las actividades necesarias y quién hacerse cargo del coste de este.

En cualquier caso, superadas todas las consideraciones expuestas, lo relevante a la hora de regular un crimen internacional contra el medio ambiente es que se respete el principio de intervención mínima del derecho penal, en general, y del derecho penal internacional, en particular. Por esto, solamente en aquellos casos en que la conducta amenace verdaderamente la vida y el desarrollo humano de forma de que la comunidad internacional no pueda ser ajena, deberá intervenir este ordenamiento. A través del castigo de los ataques más reprochables al medio ambiente mediante el derecho penal internacional, podemos reforzar la prevención de grandes desastres ambientales y la lucha contra la impunidad que, hasta el momento, preside en muchísimas ocasiones en este ámbito. Todo ello con la finalidad, en definitiva, de salvaguardar el planeta y la naturaleza, tanto para las generaciones presentes como las futuras.

\section{Referencias}

Амвоs, Kai (2004). «Derechos humanos y derecho penal internacional». Diálogo Político, 21 (3): 85-115. Disponible en bit.ly/3jS6FJo.

Atapattu, Sumudu (2002). «The Right to a Healthy Life or the Right to Die Polluted?: The Emergence of a Human Right to a Healthy Environment Under International Law». Tulane Environmental Law Journal 16 (1): 65-126. Disponible en bit. ly/36dQhOW. 
Barona VIlar, Silvia (2017). «Proceso civil y penal ¿líquido? En el siglo XXI». En Silvia Barona Vilar (editora), Justicia civil y penal en la era global. Valencia: Tirant lo Blanch.

BeCK, Ulrich (1992). Risk Society: Towards a new modernity. Londres: Sage Publications.

Berat, Lynn (1993). «Defending the Right to a Healthy Environment: Toward a Crime of Geocide in International Law». Boston University International Law Journal, 11: 327-348. Disponible en bit.ly/2HSJKk2.

BLACK, Colin L. (2008). «Crímenes contra el medio ambiente en el contexto del derecho penal internacional». Ponencia presentada en la Conferencia Once Lecciones Sobre Justicia Internacional. Zaragoza, España.

Borrás Pentinat, Susana (2014). «Del derecho humano a un medio ambiente sano al reconocimiento de los derechos de la naturaleza». Revista Vasca de Administración Pública, 99-100: 649-68o. Disponible en bit.ly/388aNmq.

Boyd, David R. (2012). The Environmental Rights Revolution: A Global Study of Constitutions, Human Rights and the Environment. Vancouver: UBC Press.

Corcoy Bidasolo, Mirentxu (2010). «Límites objetivos y subjetivos a la intervención penal en el control de riesgos». En Santiago Mir Puig y Mirentxu Corcoy Bidasolo (directores), Política criminal y reforma penal (pp. 33-54). Madrid: Edisofer.

De Luis García, Elena (2019). El derecho al medio ambiente: De su tutela penal a la respuesta procesal. Valencia: Tirant lo Blanch.

Dinstein, Yoram (2001). «Protection of the environment in international armed conflict». Max Planck Year Book of United Nations Law, 5: 523-549. Disponible en bit.ly/2HYrtBK.

Drumbl, Mark A. (1998). «Waging War against the World: The Need to Move from War Crimes to Environmental Crimes». Fordham International Law Journal, 22 (1): 122-153. Disponible en bit.ly/35ZWMEz.

EwING-CHow, Michael y Darryl Soh (2009). «Pain, Gain, or Shame: The Evolution of Environmental Law and the Role of Multinational Corporations». Indiana Journal of Global Legal Studies, 16 (1): 195-222. Disponible bit.ly/3jN6wap.

FAURE, Michael G. y Katarina Svatikova (2012). «Criminal or Administrative Law to Protect the Environment? Evidence from Western Europe». Journal of Environmental Law, 24 (2): 253-286. Disponible en bit.ly/32898JL.

Ferrete SARria, Carmen (2006). «El derecho humano: a un medio ambiente sano en el Tratado de la Constitución para Europa». Recerca: revista de pensament $i$ análisi, 6: 141-156. Disponible en bit.ly/34RmOLo.

Franco Del Pozo, Mercedes (200o). El derecho humano a un medio ambiente adecuado. Bilbao: Universidad de Deusto.

Gray, Mark Allan (1996). «The international crime of ecocide». California Western International Law Journal, 26 (2): 215-271. Disponible en bit.ly/3jSNoJk. 
HalPern, Michaela (2015). «Protecting Vulnerable Environments in Armed Conflict: Deficiencies in International Humanitarian Law». Stanford Journal of International Law, 51 (2): 119-146. Disponible en bit.ly/3jUZyjw.

Higgins, Polly (2010). Eradicating ecocide: laws and governance to prevent the destruction of our planet. Londres: Shepheard-Walwyn.

Higgins, Polly, Damien Short y Nigel South (2013). «Protecting the planet: a proposal for a law of ecocide». Crime, Law and Social Change, 59 (3): 251-266. Disponible en bit.ly/2TKiiaH.

Hiskes, Richard P. (2005). «The right to a Green Future: Human Rights, Environmentalism, and Intergenerational Justice». Human Rights Quarterly 27 (4): 13461364. Disponible en bit.ly/3jWDMvH.

Jorge Barreiro, Agustín (2005). «El bien jurídico protegido en los delitos contra el medio ambiente». En Agustín Jorge Barreiro (director), Estudios sobre la protección del medio ambiente en el ordenamiento jurídico español (pp. 1-72). Granada: Comares.

Laurenzo Copello, Patricia (2000). «Hacia la Corte Penal Internacional: los aspectos penales del Estatuto de Roma». Jueces para la Democracia, 38: 93-103. Disponible en bit.ly/3ejRQy6.

LaWrence, Peter (2015). Justice for future generations. Climate Change and Internacional Law. Cheltenham: Edward Elgar.

LaWrenCE, Jessica C. y Kevin J. Heller (2007). «The First Ecocentric Environmental War Crime: The Limits of Article 8(2)(b)(Iv) of the Rome Statute». Georgetown International Environmental Law Review, 20 (1): 61-95. Disponible en bit.ly/361krVc.

Leebaw, Bronwyn (2014). «Scorched Earth: Environmental War Crimes and International Justice». Perspectives on Politics, vol. 12, núm. 4: 770-788. https://doi. org/10.1017/S1537592714002126

Loperena Rota, Demetrio (1999). «Los derechos al Medio Ambiente adecuado y a su protección». Medio Ambiente \& Derecho: Revista Electrónica de Derecho Ambiental, 3: 1-11. Disponible en bit.ly/3mJYdOd.

-. (2008). «El derecho al desarrollo sostenible». En Antonio Embid Irujo (director), El derecho a un medio ambiente adecuado (pp. 63-83). Madrid: Iustel.

LytTon, Christopher H. (2000). «Environmental human rights: Emerging trends in international law and ecocide». Environmental Claims Journal, 13 (1): 73-91. Disponible en bit.ly/2TJmKqk.

Matellanes Rodríguez, Nuria (2008). Derecho penal del medio ambiente. Madrid: Iustel Portal Derecho.

MÉGRET, Frédéric (2011). «The Problem of an International Criminal Law of the Environment». Columbia Journal of Environmental Law, 36 (2): 195-257. Disponible en bit.ly/2TM57WT. 
Meнta, Sailesh y Prisca Merz (2015). «Ecocide - A new crime against peace?». Environmental Law Review, 17 (1): 3-7. Disponible en bit.ly/34QoscV.

Mendo Estrella, Álvaro (2007). «Problemática ambiental y derecho penal: Acerca de la necesidad y eficacia de la protección penal del medio ambiente». Anuario de La Facultad de Derecho de Alcalá de Henares: 157-193. Disponible en bit. ly/3egF6bK.

Muñoz Conde, Francisco y Mercedes García Arán (2015). Derecho penal. Parte general. 9. ${ }^{a}$ ed. Valencia: Tirant lo Blanch.

Muñoz Lorente, José (2001). «Obligaciones constitucionales de incriminación y derecho penal simbólico». Revista de Derecho y Proceso Penal, 6: 103-131. Disponible en bit.ly/3eozjZt.

NiEto Martín, Adán (2012). «Bases para un futuro derecho penal internacional del medio ambiente». Anuario de la Facultad de Derecho de la Universidad Autónoma de Madrid, 16: 137-164. Disponible en bit.ly/2HYLSab.

Pallemaerts, Marc (2002). «The human right to a healthy environment as a substantive right». En Maguelonne Déjeant-Pons y Marc Pallemaerts (editores), Human Rights and the Environment, Compendium of instruments and other international texts on individual and collective rights relating to the environment in the international and European framework (pp. 11-21). Strasbourg: Council of Europe Publishing.

Pedersen, Ole W. (2011). «European Environmental Human Rights and Environmental Rights: A long time coming?». En Dinah Shelton (editora), Human Rights and the Environment (pp. 468-498). Tomo II. Cheltenham: Edward Elgar.

Schünemann, Bernd (1997). «Principles of Criminal Legislation in Post Modern Society: The Case of Environmental Law». Buffalo Criminal Law Review, 1 (1): 175194. Disponible en bit.ly/34Ob9wn.

Sharp, Peter (1999). «Prospects for Environmental Liability in the International Criminal Court». Virginia Environmental Law Journal, 18 (2(:217-243. Disponible en bit.ly/2 $\mathrm{GoO}_{2} \mathrm{PO}$.

SHELTON, Dinah (2015). «Legitimate and necessary: adjudicating human rights violations related to activities causing environmental harm or risk». Journal of Human Rights and the Environment, 6 (2): 139-155. Disponible en bit.ly/3ehVp8d.

Sieber, Ulrich (2016). «The Paradigm Shift in the Global Risk Society: From Criminal Law to Global Security Law - An Analysis of the Changing Limits of Crime Control». Journal of Eastern-European Criminal Law, 1: 14-27. Disponible en bit. ly/360Xisg.

Silva SÁnchez, Jesús (1997). «¿Protección penal del medio ambiente? Texto y contexto del artículo 325 del código penal». La Ley: Revista Jurídica Española de Doctrina, Jurisprudencia y Bibliografía, 3: 1714-1725. Disponible en bit.ly/3oStMr1. 
-. (2001). La expansión del derecho penal: Aspectos de la política criminal en las sociedades postindustriales. 2. ${ }^{\mathrm{a}}$ ed. Madrid: Civitas.

SMITH, Tara (2013). «Creating a framework for the prosecution of environmental crimes in international criminal law». En William A. Schabas, Yvonne Mcdermott y Niamh Hayes (editores), The Ashgate Research Companion to International Criminal Law: Critical Perspectives (pp. 45-62). Abingdon: Routledge.

Vernet i Llobet, Jaume y Jordi Jaria i Manzano (2007). «El derecho a un medio ambiente sano: su reconocimiento en el constitucionalismo comparado y en el derecho internacional». Teoría y realidad constitucional, 20: 513-533. Disponible en bit.ly/35PVwnq.

Vervaele, John (2016). «International cooperation in the investigation and prosecution of environmental crime. Problems and challenges for the legislative and judicial authorities». Union of Jurists of Romania. Law Review, VI (2): 126-143. Disponible en bit.ly/2HShhuG.

\section{Sobre la autora}

Elena De Luis García es profesora ayudante doctora de Derecho Procesal en la Universidad de Valencia de España. Además, es máster en Derechos Humanos, Democracia y Justicia Internacional, y doctora en Derecho con mención Internacional por la Universidad de Valencia. Su correo electrónico es elena.deluis@uv.es. (D) https://orcid.org/0000-0001-7987-957X. 
La Revista de Derecho Ambiental, del Centro de Derecho Ambiental de la Facultad de Derecho de la Universidad de Chile, es un espacio de exposición y análisis en el plano académico del derecho ambiental. Su contenido se presenta a través de doctrina, jurisprudencia y recensiones, y aborda diversas materias relacionadas con la gestión, institucionalidad y herramientas de protección ambiental y desarrollo sustentable. Se presentan artículos de diferentes autores y autoras en los que se analizan y abordan casos y temas jurídico-ambientales de creciente interés y actualidad.

\author{
DIRECTORA \\ Valentina Durán Medina \\ EDITORES \\ Jorge Ossandón Rosales \\ y Antonio Pulgar Martínez \\ SITIO WEB \\ revistaderechoambiental.uchile.cl \\ CORREO ELECTRÓNICO \\ revistada@derecho.uchile.cl \\ LICENCIA DE ESTE ARTÍ́CULO \\ Creative Commons Atribución Compartir Igual 4.o Internacional
}

La edición de textos, el diseño editorial

y la conversión a formatos electrónicos de este artículo

estuvieron a cargo de Tipográfica

(www.tipografica.io) 